\title{
THE IMPACT OF THE JULY 2007 HEAT WAVE ON DAILY MORTALITY IN BELGRADE, SERBIA
}

\author{
Dragan C. Bogdanović1, Zoran G. Milošević², Konstansa K. Lazarević1, Zana Ć. Dolićanin ${ }^{1}$, Dragan M. \\ Ranđelović ${ }^{3}$, Stefan D. Bogdanović ${ }^{4}$ \\ 'Department of Biochemical and Medical Sciences, State University of Novi Pazar, Serbia \\ ${ }^{2}$ Faculty of Medicine, University of Niš, Serbia \\ ${ }^{3}$ Academy for Criminalistic and Police Studies Belgrade, Serbia \\ ${ }^{4}$ Public Health Institute Nišs, Serbia
}

\section{SUMMARY}

Objective: Mortality has been shown to increase with heat waves. Serbia experienced the hottest heat wave in July 2007. In this study, we examined patterns of non-traumatic excess mortality in Belgrade during this event.

Methods: The numbers of deaths observed during the 9-day heat wave were compared to those expected on the basis of mortality rates reported for the previous eight years and two following years. Excess mortality was analyzed by age, gender and cause of death.

Results: There was a total of 167 excess deaths (38\%) between 16 and 24 July. People aged 75 years and older accounted for 151 (90\%) of all excess deaths. An increase of mortality among elderly was $76 \%$ in comparison to the baseline mortality. Excess female mortality was over two times higher than excess male mortality $(54 \%: 23 \%)$. The biggest increase in mortality was from diabetes mellitus $(286 \%)$, chronic kidney disease (200\%), respiratory system diseases (73\%), and nervous system diseases (67\%). Cardiovascular and malignant neoplasms mortality accounted for the highest absolute numbers of excess deaths (77 and 49, respectively). There was no decrease in mortality in the 60-day period after the heat wave.

Conclusions: There are several causes of an increase in heat-related mortality. The most vulnerable population group is the elderly females.

Key words: climate change, heat wave, temperature, mortality, vulnerable populations

Address for correspondence: D. C. Bogdanovic, Velikotrnavska 9/13, 18000 Nis, Serbia. E-mail: draganbogdanovic@gmail.com

\section{INTRODUCTION}

The increasing instability of the global climate system is expected to increase average summer temperatures and the frequency and intensity of hot days, particularly in the northern latitudes $(1,2)$.

Heat-waves constitute a great health risk and they are associated with significant excess morbidity and mortality (3-11). Cardiovascular and respiratory diseases were reported as the most common causes of death (12-16).

Risk factors for heat-related death include older age, preexisting diseases, living alone, living on the top floor, lack of air-conditioning, and being overweight (17-18). Populations in regions where extremely hot weather is relatively infrequent are most vulnerable to heat waves due to a lack of behavioural adaptations (3). Heat waves could reveal or aggravate several adverse drug reactions in the elderly using diuretics, serotonic antidepressants, angiotensin converting inhibitors, proton pump inhibitors, non-dopaminergic antiparkinsonians or antiepileptics, and beta-blockers (19).

Some earlier studies have supported the hypotheses that high temperatures result only in the forward displacement of deaths $(20,21)$. This term denotes a temporal shift in the rate of mortality by bringing forward the deaths of those who would have died in the short term anyway.

In Serbia, the warmest heat wave was experienced between 16 and 24 July 2007. Almost on the whole territory of the country, maximum daily temperatures exceeded $35^{\circ} \mathrm{C}$ during nine consecutive days. Temperature records were broken in all districts (22). The District of Smederevska Palanka and Podunavlje District recorded the Serbia's highest ever temperature of $44.9^{\circ} \mathrm{C}$ on 24 July.

While there has been research examining the association between low outdoor temperatures and mortality in Serbia, this study is the first one that examines the influence of high outdoor temperatures on adverse health effects (23).

The aim of this article was to examine the patterns of nontraumatic excess mortality in Belgrade during the July 2007 heat wave, by age, gender and cause of death, and to define the threshold temperature above which the greatest changes in mortality occur.

\section{MATERIALS AND METHODS}

\section{Study Area}

Belgrade is the capital city of Serbia. The city has an urban area of $360 \mathrm{~km}^{2}$, while together with its metropolitan area it covers $3,223 \mathrm{~km}^{2}$, with a population of $1,639,121$ inhabitants according to the 2011 census. It lies approximately 117 metres above sea level and is located at the confluence of the Danube and Sava rivers. The coordinates of Belgrade are $40^{\circ} 49^{\prime} \mathrm{N} 20^{\circ} 28^{\prime} \mathrm{W}$. The climate is continental with the maximum temperatures observed during July or August and the highest precipitation during the summer 
months. From 1991, the natural increase is negative and present population type is regressive.

\section{Data Used}

Daily meteorological data were obtained from the Republic Hydro-meteorological Institute for the period from 1961-2009. Daily mortality database was supplied by the Statistical Office of the Republic of Serbia for the period from 1999-2009.

\section{Heat Wave Definition}

There is no universally accepted definition of heat waves, but such extreme events associated with particularly hot sustained temperatures have been known to produce notable impacts on human mortality, regional economies, and ecosystems. A heatwave can be defined based on an absolute or a relative threshold of weather variables or as a combination of both (2). The heat wave definition we adopted was based on the daily maximum temperature, after inspection of the relationship between maximum daily temperature and mortality in July 2007 in Belgrade (Fig. 1). In our definition, a heat wave is a period of at least 3 consecutive days in which the maximum temperature exceeds

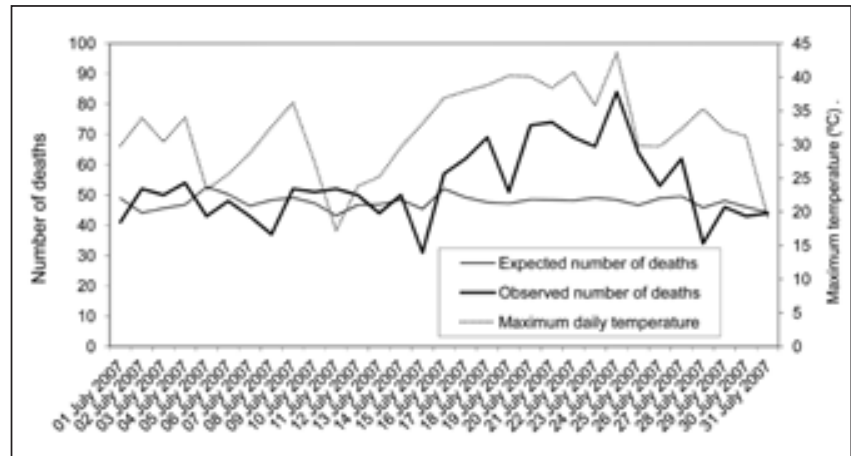

Fig. 1. Relationship between maximum daily temperature and mortality during July 2007 in Belgrade. $35^{\circ} \mathrm{C}$, which are the threshold criteria for releasing hot weather warnings in Serbia (24).

\section{Analysis}

Causes of death were analyzed according to the 10th revision of the International Classification of Diseases (ICD-10). We considered data on non-accidental mortality (ICD-10 codes A00-R99) by gender, causes of death, and age.

For heat-related deaths, hyperthermia (ICD-10 code T67), exposure to excessive natural heat (ICD-10 code X30), and deaths associated with excessive heat exposure due to weather conditions (ICD-10 code E900.0) or of unspecified origin (ICD-10 code E900.9) were analyzed.

Excess mortality was calculated as observed deaths minus the baseline expected mortality for 9-day heat wave period from 16 to 24 July 2007. Baseline values for each day were the averages of the same calendar dates in the previous eight years (1999 to 2006) and two following years (2008 and 2009).

To explore the possibility of heat-induced forward displacement of deaths we also calculated the differences between observed and expected number of deaths for 60 days following the heat wave, by 10-day lag periods.

\section{RESULTS}

Record values of the maximum daily temperatures affected Belgrade between 16 and 24 July 2007 (Table 1). The absolute temperature record was reached on 24 July with a reading of $43.6^{\circ} \mathrm{C}$, and the previous absolute maximum temperature record of $40.5^{\circ} \mathrm{C}$ dating back to 1888 was exceeded by $3.1^{\circ} \mathrm{C}$. Daily maximum temperatures exceeded mean values from the climatological standard reference period $1961-1990$ by $8.3^{\circ} \mathrm{C}$ to $15.5^{\circ} \mathrm{C}$. Also, daily minimum and mean temperatures exceeded the 1961-1990 averages by $3.0^{\circ} \mathrm{C}$ to $10.1^{\circ} \mathrm{C}$ and $6.7^{\circ} \mathrm{C}$ to $13.1^{\circ} \mathrm{C}$, respectively. In contrast, daily mean relative humidity levels during the July 2007 heat wave were lower than the 1961-1990 averages by $24 \%$ to $41 \%$.

Table 1. Daily temperature and relative humidity values during July 2007 heat wave in Belgrade, compared with mean values from the 1961-1990 period

\begin{tabular}{|c|c|c|c|c|c|c|c|c|}
\hline \multirow{3}{*}{ Calendar day } & \multicolumn{4}{|c|}{2007} & \multicolumn{4}{|c|}{$1961-1990$} \\
\hline & \multicolumn{3}{|c|}{ Temperature $\left({ }^{\circ} \mathrm{C}\right)$} & \multirow[t]{2}{*}{$\begin{array}{l}\text { Mean relative } \\
\text { humidity (\%) }\end{array}$} & \multicolumn{3}{|c|}{ Temperature $\left({ }^{\circ} \mathrm{C}\right)$} & \multirow{2}{*}{$\begin{array}{l}\text { Mean relative } \\
\text { humidity }(\%)\end{array}$} \\
\hline & Maximum & Minimum & Mean & & Maximum & Minimum & Mean & \\
\hline 16 July & 36.9 & 19.5 & 29.1 & 38 & 28.0 & 16.5 & 22.1 & 62 \\
\hline 17 July & 37.9 & 21.4 & 30.5 & 32 & 27.8 & 16.8 & 22.3 & 65 \\
\hline 18 July & 38.8 & 22.5 & 31.0 & 37 & 27.9 & 17.0 & 22.2 & 63 \\
\hline 19 July & 40.2 & 23.9 & 32.8 & 28 & 28.0 & 16.8 & 22.1 & 64 \\
\hline 20 July & 40.1 & 25.8 & 33.5 & 25 & 27.5 & 17.0 & 22.1 & 62 \\
\hline 21 July & 38.4 & 26.0 & 31.9 & 38 & 27.9 & 16.4 & 21.7 & 63 \\
\hline 22 July & 40.7 & 26.3 & 34.6 & 23 & 26.6 & 16.2 & 21.5 & 64 \\
\hline 23 July & 35.8 & 22.3 & 28.9 & 40 & 27.5 & 16.5 & 22.2 & 64 \\
\hline 24 July & 43.6 & 26.9 & 33.5 & 25 & 28.1 & 17.1 & 22.4 & 62 \\
\hline
\end{tabular}


Table 2. Number and rate (\%) of all causes non-traumatic excess deaths among overall population and elderly, during the July 2007 heat wave in Belgrade per day

\begin{tabular}{|l|c|c|c|c|c|c|c|c|}
\hline \multirow{2}{*}{$\begin{array}{l}\text { Calendar } \\
\text { day of 2007 }\end{array}$} & $\begin{array}{c}\text { Expected } \\
\text { number } \\
\text { of deaths }\end{array}$ & $\begin{array}{c}\text { Observed } \\
\text { number } \\
\text { of deaths }\end{array}$ & $\begin{array}{c}\text { Number } \\
\text { of excess } \\
\text { deaths }\end{array}$ & $\begin{array}{c}\text { Rate (\%) } \\
\text { of excess } \\
\text { deaths }\end{array}$ & $\begin{array}{c}\text { Expected } \\
\text { number } \\
\text { of deaths }\end{array}$ & $\begin{array}{c}\text { Observed } \\
\text { number } \\
\text { of deaths }\end{array}$ & $\begin{array}{c}\text { Number } \\
\text { of excess } \\
\text { deaths }\end{array}$ & $\begin{array}{c}\text { Rate (\%) } \\
\text { of excess } \\
\text { deaths }\end{array}$ \\
\hline 16 July & 52 & 57 & 5 & 10 & 22 & 29 & 7 & 32 \\
\hline 17 July & 49 & 62 & 13 & 27 & 22 & 30 & 8 & 38 \\
\hline 18 July & 48 & 69 & 21 & 44 & 22 & 42 & 20 & 90 \\
\hline 19 July & 47 & 51 & 4 & 9 & 20 & 29 & 9 & 48 \\
\hline 20 July & 49 & 73 & 24 & 49 & 22 & 42 & 20 & 88 \\
\hline 21 July & 48 & 74 & 26 & 54 & 22 & 40 & 18 & 84 \\
\hline 22 July & 48 & 69 & 21 & 44 & 21 & 45 & 24 & 114 \\
\hline 23 July & 49 & 66 & 17 & 35 & 25 & 39 & 14 & 59 \\
\hline 24 July & 48 & 84 & 36 & 75 & 24 & 54 & 30 & 124 \\
\hline Total & 438 & 605 & 167 & 38 & 199 & 350 & 151 & 76 \\
\hline
\end{tabular}

Table 2 shows the daily distributions of deaths attributed to the July 2007 heat wave in Belgrade. There was a total of 167 excess deaths (38\% increase) between 16 and 24 July. For the hottest day of 24 July, 36 excess deaths were observed, $75 \%$ increase in comparison with the baseline expected mortality.

People aged 75 years and older accounted for 151 (90\%) of all excess deaths. An increase in mortality among elderly was $76 \%$ in comparison with the baseline mortality, and for the day of 24 July it reached $124 \%$.

Table 3 shows that during the July 2007 heat wave in Belgrade the biggest increase in mortality was related to diabetes mellitus (286\%), chronic kidney disease $(200 \%)$, respiratory system diseases $(73 \%)$, and nervous system diseases (67\%). Cardiovascular and malignant neoplasms mortality accounted for the highest absolute numbers of excess deaths (77 and 49, respectively).

During the heat wave excess mortality among females was over two times higher than among males (54\%: $23 \%)$. Among females, the greatest increases in mortality were related to chronic kidney disease (200\%), diabetes mellitus (175\%), nervous system diseases (100\%), and digestive system diseases (86\%). Among males, mortality related to diabetes mellitus (433\%), chronic kidney disease (200\%) and respiratory system diseases (86\%) showed the biggest increase.

There was only one case documented in the death certificate as heat-related death during the July 2007 heat wave in Belgrade. The deceased was 55 years old male with hyperthermia denoted as underlying cause of death and with exposure to excessive natural heat recorded as a contributing factor. There were no other cases with ICD-10 codes for hyperthermia, exposure to excessive natural heat or deaths associated with excessive heat exposure documented in the death certificate, neither as underlying cause of death nor as contributing factor.

There was not a significant subsequent drop below expected levels of mortality from all causes during the 60-day period after the July 2007 heat wave in Belgrade (Table 4). Differences between observed and expected number of deaths varied from +26 (6\% increase) in Lag 0-10 to -17 (4\% decrease) in Lag 41-50, and cumulative difference after 60 days was +36 ( $1 \%$ increase).

\section{DISCUSSION}

An extreme heat wave affected Serbia including Belgrade in July 2007 and it was accompanied by a significant short-term excess mortality. Increased mortality occurred on 16 July when the maximum daily temperature surpassed $35^{\circ} \mathrm{C}$, it amounted to 167 excess deaths (38\% increase comparing to expected deaths) for nine consecutive days of heat, with a progressive return to almost normal mortality as the maximum temperature dropped below $35^{\circ} \mathrm{C}$ on $25 \mathrm{July}$. Such relationship between maximum daily temperature and mortality during July 2007 in Belgrade supporting the evidence for acclimatization. Some studies reported that people who live in the cities where the temperatures are generally elevated in the summer were found to have higher threshold mortality temperatures than people who live in the cities with milder climates (25).

The heat effect on mortality was concentrated in people aged 75 years and older, and they accounted for 151 (90\%) of all excess deaths. The elderly are especially vulnerable to extreme heat because their bodies are less able to effectively regulate temperature. Their risk is further heightened because the elderly often have diminished health and are more likely to live alone (15). They are more likely to have a combination of factors, including the effects of ageing, chronic medical conditions and disability, taking medication, and social factors.

The heat effect was more noticeable in females, resulting in mortality increases as large as $54 \%$ compared to $23 \%$ among males. The fact is that more women reached older ages and older people become more susceptible to death due to heat.

In line with many previous studies, we found that during the heat wave the greatest increase in mortality rates was related to diabetes mellitus, chronic kidney disease and to diseases of respiratory, nervous and digestive systems $(12,15,16,26)$. Cardiovascular and malignant neoplasms mortality accounted for the highest absolute numbers of excess deaths $(4,12)$.

People with diabetes are particularly vulnerable to heat because their bodies are less capable of adjusting to increases in temperature due to impairment of their autonomic control and 
Table 3. Excess mortality and mean age of death during the 9-day July 2007 heat wave in Belgrade, by gender and cause of death

\begin{tabular}{|c|c|c|c|c|c|}
\hline Cause of death (ICD-10 code) & $\begin{array}{c}\text { Expected } \\
\text { number of } \\
\text { deaths }\end{array}$ & $\begin{array}{c}\text { Observed } \\
\text { number of } \\
\text { deaths }\end{array}$ & $\begin{array}{c}\text { Number of } \\
\text { excess deaths }\end{array}$ & $\begin{array}{c}\text { Rate }(\%) \text { of } \\
\text { excess deaths }\end{array}$ & $\begin{array}{c}\text { Mean age of } \\
\text { death } \pm \text { SD }\end{array}$ \\
\hline Overall population & 438 & 605 & 167 & 38 & $74,07 \pm 12,00$ \\
\hline Neoplasms (C00-D48) & 110 & 159 & 49 & 45 & $68,06 \pm 13,01$ \\
\hline Endocrine diseases (E00-E90) & 7 & 27 & 20 & 286 & $72,59 \pm 10,18$ \\
\hline Diabetes mellitus (E10-E14) & 7 & 27 & 20 & 286 & $72,59 \pm 10,18$ \\
\hline Nervous system diseases (G00-G99) & 6 & 10 & 4 & 67 & $70,60 \pm 11,30$ \\
\hline Circulatory system diseases (100-199) & 235 & 312 & 77 & 33 & $77,80 \pm 9,77$ \\
\hline Respiratory system diseases (J00-J99) & 11 & 19 & 8 & 73 & $78,74 \pm 5,42$ \\
\hline Digestive system diseases (K00-K93) & 17 & 23 & 6 & 35 & $65,43 \pm 13,47$ \\
\hline Genitourinary system diseases (N00-N99) & 6 & 16 & 10 & 167 & $73,69 \pm 10,87$ \\
\hline Chronic kidney disease (N18) & 4 & 12 & 8 & 200 & $74,92 \pm 9,00$ \\
\hline Symptoms, signs and findings (R00-R99) & 38 & 32 & -6 & -16 & $74,77 \pm 15,01$ \\
\hline Other causes & 8 & 7 & -1 & -12 & $75,00 \pm 5,23$ \\
\hline Males & 227 & 280 & 53 & 23 & $73,06 \pm 12,13$ \\
\hline Neoplasms (C00-D48) & 63 & 78 & 15 & 24 & $67,94 \pm 11,58$ \\
\hline Endocrine diseases (E00-E90) & 3 & 16 & 13 & 433 & $73,13 \pm 9,53$ \\
\hline Diabetes mellitus (E10-E14) & 3 & 16 & 13 & 433 & $73,13 \pm 9,53$ \\
\hline Nervous system diseases (G00-G99) & 3 & 4 & 1 & 33 & $74,25 \pm 2,87$ \\
\hline Circulatory system diseases (100-199) & 109 & 126 & 17 & 16 & $77,01 \pm 11,05$ \\
\hline Respiratory system diseases (J00-J99) & 7 & 13 & 6 & 86 & $78,77 \pm 5,77$ \\
\hline Digestive system diseases (K00-K93) & 10 & 10 & 0 & 0 & $63,00 \pm 11,06$ \\
\hline Genitourinary system diseases (N00-N99) & 4 & 9 & 5 & 125 & $71,11 \pm 13,60$ \\
\hline Chronic kidney disease (N18) & 2 & 6 & 4 & 200 & $74,33 \pm 12,86$ \\
\hline Symptoms, signs and findings (R00-R99) & 24 & 20 & -4 & -17 & $71,05 \pm 15,71$ \\
\hline Other causes & 4 & 4 & 0 & 0 & $77,00 \pm 5,75$ \\
\hline Females & 211 & 325 & 114 & 54 & $74,95 \pm 11,85$ \\
\hline Neoplasms (C00-D48) & 47 & 81 & 34 & 72 & $68,22 \pm 14,24$ \\
\hline Endocrine diseases (E00-E90) & 4 & 11 & 7 & 175 & $71,82 \pm 11,49$ \\
\hline Diabetes mellitus (E10-E14) & 4 & 11 & 7 & 175 & $71,82 \pm 11,49$ \\
\hline Nervous system diseases (G00-G99) & 3 & 6 & 3 & 100 & $68,17 \pm 14,39$ \\
\hline Circulatory system diseases (100-199) & 126 & 186 & 60 & 48 & $78,34 \pm 8,79$ \\
\hline Respiratory system diseases (J00-J99) & 4 & 6 & 2 & 50 & $78,67 \pm 5,09$ \\
\hline Digestive system diseases (K00-K93) & 7 & 13 & 6 & 86 & $67,31 \pm 15,23$ \\
\hline Genitourinary system diseases (NO0-N99) & 2 & 7 & 5 & 250 & $77,00 \pm 5,07$ \\
\hline Chronic kidney disease (N18) & 2 & 6 & 4 & 200 & $75,50 \pm 3,45$ \\
\hline Symptoms, signs and findings (R00-R99) & 14 & 12 & -2 & -14 & $81,18 \pm 11,71$ \\
\hline Other causes & 4 & 3 & -1 & -25 & $75,00 \pm 3,66$ \\
\hline
\end{tabular}

endothelial function (28). Persons with kidney disease have a reduced ability to retain fluids and electrolytes. This can make dehydration and overheating happen more quickly. Moreover, when the body gets warm, it moves more blood to the skin in an attempt to reduce body temperature. This reduces both the blood flow and pressure in the kidneys making them more prone to overheating and less able to function (28). The mechanisms underlying the higher heat-mortality risk among those with nervous system diseases include impaired self-care, inadequate medical care and physiologic vulnerability (29). Heat stress can lead to down-regulation of epithelial growth-factor signalling, intestinal epithelial injury, impairment of the intestinal epithelial barrier function, and increased mortality due to gastrointestinal hemorrhage (30). Cardiovascular and respiratory deaths can be triggered by heat when the thermoregulatory mechanisms of the body, such as increased respiratory and heart rate, increased surface blood circulation and sweat, put an additional stress on already ill heart and lungs (31). 
Table 4. Differences between observed and expected number of all causes deaths in 60 days following the July 2007 heat wave in Belgrade, by 10-day lag

\begin{tabular}{|l|c|c|c|c|c|c|c|c|}
\hline Lag (days) & $\begin{array}{c}\text { Expected } \\
\text { number } \\
\text { of deaths }\end{array}$ & $\begin{array}{c}\text { Observed } \\
\text { number } \\
\text { of deaths }\end{array}$ & Difference & $\begin{array}{c}\text { Rate (\%) } \\
\text { of difference }\end{array}$ & $\begin{array}{c}\text { Cumulative } \\
\text { expected } \\
\text { number } \\
\text { of deaths }\end{array}$ & $\begin{array}{c}\text { Cumulative } \\
\text { observed } \\
\text { number } \\
\text { of deaths }\end{array}$ & $\begin{array}{c}\text { Cumulative } \\
\text { difference }\end{array}$ & $\begin{array}{c}\text { Rate (\%) } \\
\text { of cumulative } \\
\text { difference }\end{array}$ \\
\hline $0-10$ & 471 & 497 & 26 & 6 & 471 & 497 & 26 & 6 \\
\hline $11-20$ & 471 & 470 & -1 & 0 & 942 & 967 & 25 & 3 \\
\hline $21-30$ & 490 & 515 & 25 & 5 & 1432 & 1482 & 50 & 3 \\
\hline $31-40$ & 467 & 464 & -3 & -1 & 1899 & 1946 & 47 & 2 \\
\hline $41-50$ & 474 & 457 & -17 & -4 & 2373 & 2403 & 30 & 1 \\
\hline $51-60$ & 472 & 478 & 6 & 1 & 2845 & 2881 & 36 & 1 \\
\hline
\end{tabular}

We did not observe a decrease in mortality in the 60-day period after the heat wave. This suggests that not only a pool of frail individuals was impacted by the exposure, but also that the heat waves is a real public health issue (25).

The association between high outdoor temperature exposure and mortality could be modified by increased summer-time oxidation smog as well as the indoor living conditions (27, 32-34). However, the influence of these two factors was not examined, which represents a limitation to this study.

\section{CONCLUSION}

The results of this study indicate increased health risks during the July 2007 heat wave in Belgrade. The most affected were the elderly, women, people with diabetes mellitus, chronic kidney disease, respiratory, nervous, digestive and cardiovascular systems diseases and malignant neoplasms. Mortality increased when the maximum daily temperature rose above $35^{\circ} \mathrm{C}$. Heat-induced forward displacement of deaths was not confirmed. Heat waves have a significant burden on health, and as global warming continues, they are very likely to increase in frequency and intensity.

\section{Acknowledgements}

Presented results are the part of the project 44007 financed by the Ministry of Science and Technological Development, the Republic of Serbia.

\section{REFERENCES}

1. McGeehin MA, Mirabelli M. The potential impacts of climate variability and change on temperature-related morbidity and mortality in the United States. Environ Health Perspect. 2001 May;109 Suppl 2:185-9.

2. Meehl GA, Tebaldi C. More intense, more frequent, and longer lasting heat waves in the 21st century. Science. 2004 Aug 13;305(5686):994-7.

3. Pirard P, Vandentorren S, Pascal M, Laaidi K, Le Tertre A, Cassadou S, et al. Summary of the mortality impact assessment of the 2003 heat wave in France. Euro Surveill. 2005 Jul;10(7):153-6.

4. Le Tertre A, Lefranc A, Eilstein D, Declercq C, Medina S, Blanchard M, et al. Impact of the 2003 heat wave on all-cause mortality in 9 French cities. Epidemiology. 2006 Jan;17(1):75-9.

5. Johnson H, Kovats RS, McGregor G, Stedman J, Gibbs M, Walton H, et al. The impact of the 2003 heat wave on mortality and hospital admissions in England. Health Stat Q. 2005 Spring;(25):6-11.

6. Nogueira PJ, Falcão JM, Contreiras MT, Paixão E, Brandão J, Batista I. Mortality in Portugal associated with the heat wave of August 2003: early estimation of effect, using a rapid method. Euro Surveill. 2005 Jul;10(7):150-3.
7. Simón F, Lopez-Abente G, Ballester E, Martínez F. Mortality in Spain during the heat waves of summer 2003. Euro Surveill. 2005 Jul;10(7):15661.

8. Garssen J, Harmsen C, de Beer J. The effect of the summer 2003 heat wave on mortality in the Netherlands. Euro Surveill. $2005 \mathrm{Jul} ; 10$ (7):165-8.

9. Michelozzi P, de Donato F, Bisanti L, Russo A, Cadum E, DeMaria M, et al. The impact of the summer 2003 heat waves on mortality in four Italian cities. Euro Surveill. 2005 Jul;10(7):161-5.

10. Grize L, Huss A, Thommen O, Schindler C, Braun-Fahrländer C. Heat wave 2003 and mortality in Switzerland. Swiss Med Wkly. 2005 Apr 2;135(13-14):200-5.

11. Reid CE, O'Neill MS, Gronlund CJ, Brines SJ, Brown DG, Diez-Roux $\mathrm{AV}$, et al. Mapping community determinants of heat vulnerability. Environ Health Perspect. 2009 Nov;117(11):1730-6.

12. Basagaña X, Sartini C, Barrera-Gómez J, Dadvand P, Cunillera J, Ostro B, et al. Heat waves and cause-specific mortality at all ages. Epidemiology. 2011 Nov;22(6):765-72.

13. Barnett AG, Hajat S, Gasparrini A, Rocklöv J. Cold and heat waves in the United States. Environ Res. 2012 Jan;112:218-24.

14. Curriero FC, Heiner KS, Samet JM, Zeger SL, Strug L, Patz JA. Temperature and mortality in 11 cities of the eastern United States. Am J Epidemiol. 2002 Jan 1;155(1):80-7.

15. Medina-Ramón M, Zanobetti A, Cavanagh DP, Schwartz J. Extreme temperatures and mortality: assessing effect modification by personal characteristics and specific cause of death in a multi-city case-only analysis. Environ Health Perspect. 2006 Sep;114(9):1331-6.

16. Basu R, Samet JM. Relation between elevated ambient temperature and mortality: a review of the epidemiologic evidence. Epidemiol Rev. 2002;24(2):190-202

17. Kilbourne EM, Choi K, Jones TS, Thacker SB. Risk factors for heatstroke. A case-control study. JAMA. 1982 Jun 25;247(24):3332-6.

18. Semenza JC, Wilson DJ, Parra J, Bontempo BD, Hart M, Sailor DJ, et al. Public perception and behavior change in relationship to hot weather and air pollution. Environ Res. 2008 Jul;107(3):401-11

19. Sommet A, Durrieu G, Lapeyre-Mestre M, Montastruc JL; Association of French PharmacoVigilance Centres. A comparative study of adverse drug reactions during two heat waves that occurred in France in 2003 and 2006. Pharmacoepidemiol Drug Saf. 2012 Mar;21(3):285-8.

20. Rooney C, McMichael AJ, Kovats RS, Coleman MP. Excess mortality in England and Wales, and in Greater London, during the 1995 heat wave. J Epidemiol Community Health. 1998 Aug;52(8):482-6.

21. Eng H, Mercer JB. Seasonal variations in mortality caused by cardiovascular diseases in Norway and Ireland. J Cardiovasc Risk. 1998 Apr;5(2):89-95.

22. Unkasevic M, Tosic I. The maximum temperatures and heat waves in Serbia during the summer of 2007. Climatic Change. 2011;108(1-2):20723.

23. Blagojević LM, Bogdanović DC, Jović SJ, Milosević ZG, Dolićanin ZC. Excess winter mortality of Roma population in Serbia, 1992-2007. Cent Eur J Public Health. 2012 Jun;20(2):135-8.

24. Koppe C, Kovats S, Jendritzky G, Menne B. Heat-waves: risks and responses. Health and global environmental change series, no. 2 [Internet]. Copenhagen: WHO Regional Office for Europe; 2004 [cited 2013 Sep 13]. Available from: http://www.euro.who.int/document/E82629.pdf.

25. Basu R. High ambient temperature and mortality: a review of epidemiologic studies from 2001 to 2008. Environ Health. 2009 Sep 16;8:40. 
26. Stafoggia M, Forastiere F, Agostini D, Biggeri A, Bisanti L, Cadum E, et al. Vulnerability to heat-related mortality: a multicity, population-based, case-crossover analysis. Epidemiology. 2006 May;17(3):315-23.

27. Schwartz J. Who is sensitive to extremes of temperature?: A case-only analysis. Epidemiology. 2005 Jan;16(1):67-72.

28. Hansen AL, Bi P, Ryan P, Nitschke M, Pisaniello D, Tucker G. The effect of heat waves on hospital admissions for renal disease in a temperate city of Australia. Int J Epidemiol. 2008 Dec;37(6):1359-65.

29. Hansen A, Bi P, Nitschke M, Ryan P, Pisaniello D, Tucker G. The effect of heat waves on mental health in a temperate Australian city. Environ Health Perspect. 2008 Oct;116(10):1369-75.

30. Liu F, Yin J, Du M, Yan P, Xu J, Zhu X, et al. Heat-stress-induced damage to porcine small intestinal epithelium associated with downregulation of epithelial growth factor signaling. J Anim Sci. 2009 Jun;87(6):1941-9.

31. Schifano P, Cappai G, De Sario M, Michelozzi P, Marino C, Bargagli AM, et al. Susceptibility to heat wave-related mortality: a follow-up study of a cohort of elderly in Rome. Environ Health. 2009 Nov 12;8:50.
32. Goldberg MS, Burnett RT, Brook J, Bailar JC 3rd, Valois MF, Vincent R. Associations between daily cause-specific mortality and concentrations of ground-level ozone in Montreal, Quebec. Am J Epidemiol. 2001 Nov $1 ; 154(9): 817-26$

33. Stafoggia M, Forastiere F, Faustini A, Biggeri A, Bisanti L, Cadum E, et al.; EpiAir Group. Susceptibility factors to ozone-related mortality: a population-based case-crossover analysis. Am J Respir Crit Care Med. 2010 Aug 1;182(3):376-84.

34. O'Neill MS. Air conditioning and heat-related health effects. Appl Environ Sci Publ Health. 2003;1(1):9-12.

Received September 14, 2012 Accepted in revised form June 2, 2013 